\title{
The Impact of General Medical Conditions in Obsessive-Compulsive Disorder
}

\author{
Andrea Aguglia $^{1 凶}$, Maria Salvina Signorelli $^{2}$, Umberto Albert ${ }^{1}$, and Giuseppe Maina ${ }^{1}$ \\ 1“Rita Levi Montalcini” Department of Neuroscience, University of Turin, Psychiatric Unit, San Luigi Gonzaga Hospital, Orbassano, Turin, Italy \\ ${ }^{2}$ Department of Clinical and Experimental Medicine, AOU Policlinico Hospital, University of Catania, Catania, Italy
}

Objective The co-occurrence of general medical conditions (GMCs) and major psychiatric disorders is well documented. The aim of this study was to assess the prevalence of GMCs in patients with a primary diagnosis of obsessive-compulsive disorder (OCD) and, secondly, to investigate which clinical variables are associated with the presence of a GMC.

Methods Subjects with a primary diagnosis of OCD were included. Socio-demographic and clinical characteristics were collected. GMCs were classified using the ICD-10 and grouped according to the Cumulative Illness Rating Scale (CIRS) in: cardiac, vascular, hematopoietic, respiratory, ear/nose/throat, upper and lower gastrointestinal, hepatic, renal, genitourinary, musculoskeletal, neurologic, endocrine/metabolic. The association between the presence of GMCs and demographic/clinical variables of OCD was investigated.

Results A total of 162 patients with OCD were included. 78 (48.1\%) patients had at least one comorbid GMC. Most frequent GMCs were endocrine/metabolic diseases (25.9\%), followed by upper/lower gastrointestinal (20.5\%) and cardio-vascular diseases (13.6\%). The presence of a GMC was significantly associated with female gender, older age, duration of untreated illness (DUI), and absence of physical activity.

Conclusion Patients with OCD have high rates of comorbid GMCs. A longer DUI is associated with having at least one GMCs; this might be due to the long-lasting adoption of unhealthy lifestyles, not counterbalanced by appropriate treatment and psychoeducation.

Psychiatry Investig 2018;15(3):246-253

Key Words Obsessive-compulsive disorder, General medical condition, Cardiovascular disease, Duration of untreated illness, Medical illness.

\section{INTRODUCTION}

The National Comorbidity Survey Replication (NCS-R) in the US found that at least $68 \%$ of subjects with a psychiatric disorder had at least one comorbid general medical condition (GMC), while $29 \%$ of those with a GMC had at least a comorbid psychiatric disorder. ${ }^{1}$ A population study, conducted in Singapore, found that the rate of any physical disorder in those with psychiatric disorders was $50.6 \%{ }^{2}$ Several other studies confirmed that psychiatric disorders frequently co-occur with GMCs ${ }^{3-5}$ and this co-occurrence has been par-

Received: December 7, 2016 Revised: June 4, 2017

Accepted: June 17, 2017

$\triangle$ Correspondence: Andrea Aguglia, MD

"Rita Levi Montalcini” Department of Neuroscience, University of Turin, Psychiatric Unit, San Luigi Gonzaga Hospital, Regione Gonzole 10-10043 Orbassano, Turin, Italy

Tel: +39 011/9026659, Fax: +39 011/9026504,E-mail: andrea.aguglia@unito.it

(a) This is an Open Access article distributed under the terms of the Creative Commons Attribution Non-Commercial License (http://creativecommons.org/licenses/bync/4.0) which permits unrestricted non-commercial use, distribution, and reproduction in any medium, provided the original work is properly cited. ticularly documented in patients affected by bipolar disorder, schizophrenia and depressive disorders. ${ }^{6-8}$

The high occurrence of GMCs in patients with mental disorders can be explained in three ways: the impact of psychopharmacological treatments (mainly second-generation antipsychotics), illness-related factors such as the adoption of unhealthy lifestyles associated with the psychiatric disorder itself (i.e., increased caloric intake, cigarette smoking, alcohol use and low physical activity), and probably inherited biological factors such as hypothalamic pituitary adrenal axis dysregulation. For example, in a recent review study, Mansur and coworkers concluded that obesity and mood disorders are intrinsically linked and share a series of clinical, neurobiological, genetic and environmental predisposing factors. ${ }^{9}$

Several research and review studies evaluated the prevalence of GMCs in patients with bipolar disorder or schizophrenia. These patients suffer more frequently from cardiovascular diseases, hypertension, diabetes, endocrine diseases such as hypo-hyperthyroidism, respiratory diseases such as 
asthma or chronic obstructive pulmonary illness, liver and/or renal conditions, peptic ulcer, and arthritis..$^{10-12}$

The relationship between anxiety disorders or obsessivecompulsive spectrum disorders and GMCs is less documented. Some studies found significant associations between anxiety disorders and cardiac disorders, hypertension, gastrointestinal problems, genitourinary disorders and migraine. ${ }^{13-15} \mathrm{On}$ the other hand, clinical studies also suggested that anxiety disorders could be an early manifestation of GMCs. ${ }^{16-18}$ Only few studies investigated prevalence rates of metabolic syndrome (MetS) in patients with a primary diagnosis of anxiety disorders; rates of MetS, from $21.2 \%$ to $47.8 \%$, are higher than those in the general population. ${ }^{19-23}$ In OCD patients, the long-term (1-year) use of antipsychotics added to SRIs has been associated with an increase in body mass index and fasting blood sugar. $^{24}$ Moreover, the use of a long-term antidepressant therapy (serotonin reuptake inhibitors) is also associated with a significant weight gain. ${ }^{25}$

Despite the considerable body of research examining GMCs in other psychiatric disorders, there is little research examining the physical health of patients with OCD: as a result, comorbid GMCs may be underdiagnosed and undertreated in clinical practice in subjects with OCD.

The aim of this study was to assess the prevalence of GMCs in patients with a primary diagnosis of OCD and, secondly, to investigate which clinical variables are associated with the presence of a GMC.

\section{METHODS}

\section{Subjects}

The study had a naturalistic design and involved patients with a primary diagnosis of OCD consecutively admitted to the Mood and Anxiety Disorders Unit, Department of Neuroscience, University of Turin (Italy) from January 2013 to December 2015. This is a tertiary referral center mainly for patients from Piedmont and Aosta's Valley regions, located within the University General Hospital, specialized in the treatment of patients with OCD.

Subjects with a principal diagnosis of OCD according to the DSM-IV TR, with a minimum total score of 16 on the YaleBrown Obsessive Compulsive Scale (Y-BOCS) and with at least 18 years old were included in the study.

Exclusion criteria were: primary diagnosis of schizophrenia, schizoaffective disorder, bipolar disorder, delusional disorder, severe personality disorders (such as borderline and antisocial), substance use disorders; pregnancy or recently given birth, refusal to sign the informed consent before starting the study.

Participants expressed willingness to take part in the study by signing a written consent after the aims of the study and study procedures were thoroughly explained. All subjects were of Caucasian Italian origin. The study design was reviewed by the local ethics committee.

\section{Assessments and procedures}

Data were obtained through the administration of a semistructured interview, used in our previous studies ${ }^{23,25}$ with a format that covered the following areas: socio-demographic data, diagnostic evaluation (by means of the Structured Clinical Interview for DSM-IV Axis I and II Disorders), age at onset of OCD, duration of untreated illness (DUI), defined as time from onset of the disorder to first correct treatment received, body mass index (BMI). Lifestyles were also investigated: information about exposure to cigarette smoking and physical exercise were obtained by directly interviewing the patients. A score was assigned to the frequency of physical exercise: absent, mild ( $<4 \mathrm{~h} /$ week), moderate $(4 \mathrm{~h} /$ week with a tolerance of $\pm 30 \mathrm{~min}$ ) and intense ( $>4 \mathrm{~h} /$ week, regular).

In addition, the following rating scales were included in the assessment: Y-BOCS, Hamilton Anxiety Rating Scale (HAMA), Hamilton Depression Rating Scale (HAM-D), Clinical Global Illness - Severity (CGI-S).

The inter-rater reliability of DSM-IV diagnoses using the SCID-I was tested before the beginning of the study $(>0.80$ for the presence of any lifetime Axis I disorders). Inter-rater reliabilities of the Y-BOCS, HAM-A and HAM-D total scores were also $\operatorname{good}(>0.80)$.

The presence of GMCs was investigated using ICD-10 diagnoses; moreover, we grouped GMCs according to the $\mathrm{Cu}$ mulative Illness Rating Scale (CIRS) ${ }^{26}$ as follows: cardiac, vascular, hematopoietic, respiratory, ear/nose/throat, upper and lower gastrointestinal, hepatic, renal, genitourinary, musculoskeletal, neurologic, and endocrine/metabolic.

\section{Statistical analysis}

All statistical analyses were performed using SPSS version 20.0 (IBM Corp., Armonk, NY, USA) and the value of statistical significance was set at $\mathrm{p}<0.05$.

The socio-demographic and clinical characteristics of the subjects were represented as mean and standard deviation (SD) for continuous variables and in terms of frequency and percentage regarding categorical variables. GMCs according to CIRS system were summarized as percentages.

The sample was divided in two subgroups according to the presence/absence of at least one GMC. In order to analyze differences between these two subgroups, we used the Pearson $\chi^{2}$ test with Yates correction for the comparison of categorical variables, and t-test for independent samples for continuous variables.

A logistic regression analysis was finally used to explore the 
relationship between the presence of GMCs in patients with OCD (dependent variable) and each of the other independent variables previously found associated in the statistical analyses. The probability of entering the equation was set at 0.05 .

\section{RESULTS}

We reported data on 162 patients with a primary diagnosis of OCD. We excluded $30 \mathrm{BD}$ or schizophrenia patients with comorbid OCD. Other 12 patients were excluded because they declined to participate. Lastly, six patients showed a YBOCS total score inferior to 16 after initial assessment and therefore they were not considered for this study.

Patients had a mean age of $35.6 \pm 14.4$ years; 96 (59.3\%) were males. Mean age at onset of OCD was $19.3 \pm 7.3$ years, with a mean DUI of $115.9 \pm 113.6$ months. Socio-demographic and clinical characteristics of subjects included in the present study are summarized in Table 1.

A total of $78(48.1 \%)$ patients had at least one comorbid GMC. Most frequent GMCs were endocrine/metabolic diseases (25.9\%), followed by upper/lower gastrointestinal (20.5\%)

Table 1. Socio-demographic and clinical characteristics of all subjects included $(\mathrm{N}=162)$

\begin{tabular}{|c|c|}
\hline & All sample \\
\hline Male gender, $\mathrm{N}(\%)$ & $96(59.3)$ \\
\hline Age (years), mean $\pm S D$ & $35.6 \pm 14.4$ \\
\hline Education (years), mean $\pm \mathrm{SD}$ & $12.6 \pm 3.7$ \\
\hline \multicolumn{2}{|l|}{ Marital status, N (\%) } \\
\hline Single & $108(66.7)$ \\
\hline Married & $44(27.2)$ \\
\hline Separated & $6(3.7)$ \\
\hline Widowed & $4(2.4)$ \\
\hline Occupational status, $\mathrm{N}(\%)$ & $98(60.5)$ \\
\hline Age at onset (years), mean \pm SD & $19.3 \pm 7.3$ \\
\hline Duration of untreated illness (months), mean $\pm \mathrm{SD}$ & $115.9 \pm 113.6$ \\
\hline Cigarette smoking, N (\%) & $40(24.7)$ \\
\hline Physical activity, N (\%) & $104(64.2)$ \\
\hline Absent & $58(35.8)$ \\
\hline Mild & $66(40.7)$ \\
\hline Moderate & $30(18.5)$ \\
\hline Intense & $8(4.9)$ \\
\hline Yale-Brown Obsessive-Compulsive Scale, mean \pm SD & $25.6 \pm 6.1$ \\
\hline Obsession score & $12.9 \pm 3.1$ \\
\hline Compulsion score & $12.7 \pm 3.5$ \\
\hline Hamilton Depression Rating Scale, mean \pm SD & $11.7 \pm 6.3$ \\
\hline Hamilton Anxiety Rating Scale, mean \pm SD & $11.3 \pm 5.5$ \\
\hline Clinical Global Illness-Severity, mean \pm SD & $3.8 \pm 0.9$ \\
\hline Body Mass Index, mean \pm SD & $25.7 \pm 5.5$ \\
\hline
\end{tabular}

SD: standard deviation, $\mathrm{N}$ : number and cardio-vascular diseases (13.6\%). Among endocrine/metabolic diseases, most frequent conditions were hypercholesterolemia ( $n=40,24.7 \%)$, hypo/hyper-thyroidism $(n=22,13.6 \%)$, ten cases of diabetes mellitus (6.2\%) (two insulin-dependent diabetes mellitus). Among upper/lower gastrointestinal diseases, most frequent conditions were gastroesophageal reflux $(n=25,15.4 \%)$, Gilbert's syndrome $(n=10,6.2 \%)$, seven cases (4.3\%) of chronic intestinal inflammatory diseases and cholelithiasis. Lastly, among cardio-vascular disease, most frequent conditions were hypertension $(n=20,12.3 \%)$, anemia $(n=13$, $8.0 \%$ ), and eight cases (4.9\%) of valvular heart diseases. According to NCEP ATP III, 32 patients (19.8\%) met the criteria for metabolic syndrome.

Regarding pharmacological treatment, the vast majority of patients were taking medium-to-high doses of serotonin reuptake inhibitors (SRIs) according to International guidelines. Some patients were taking also low dosage antipsychotics (mainly aripiprazole, olanzapine or risperidone) as augmentation treatment. Table 2 shows current pharmacological treatment of subjects with or without GMC. No significant differences were found between the two groups.

When we divided our sample according to the presence/absence of at least one GMC and compared the two subgroups, patients with GMCs were more frequently females (56.4\% vs. $26.2 \%, \mathrm{p}=0.006)$, were older $(42.0 \pm 15.4$ vs. $29.7 \pm 10.6$ years, $\mathrm{p}<0.001)$, had a longer DUI ( $153.0 \pm 134.9$ vs. $77.0 \pm 80.7$ months, $\mathrm{p}=0.003)$, and had no physical activity ( $51.3 \%$ vs. $76.2 \%, \mathrm{p}=0.019)$ (Table 3).

However, when we performed a stepwise logistic regression analysis, the duration of untreated illness no longer predicted the presence of a GMC (Table 4).

\section{DISCUSSION}

The primary aim of our study was to assess the prevalence of GMCs in patients with OCD. The prevalence of at least one GMC was $48.1 \%$ in our sample, demonstrating the high occurrence of physical morbidity in subjects with OCD. Different models have been proposed to explain the high co-occurrence of anxiety disorders in general and physical diseases: anxiety may be a consequent or antecedent factor of a physical illness, third variables may lead to the comorbidity or, common genetic, environmental or personality factors may contribute to the co-occurrence. ${ }^{27}$

The most prevalent GMCs were endocrine/metabolic diseases $(25.9 \%)$ while the prevalence of metabolic syndrome was $19.8 \%$. This result is in line with our previous study in OCD subjects where the MetS prevalence was $21.2 \%{ }^{23}$ : to the best of our knowledge, no other studies on MetS in OCD patients were conducted and, although we could not perform any di- 
Table 2. Pharmacological treatment of patients with OCD with and without GMC

\begin{tabular}{|c|c|c|c|c|}
\hline & No GMC $(\mathrm{N}=84)$ & GMC $(\mathrm{N}=78)$ & $t / \chi^{2}$ & $\mathrm{p}$ \\
\hline No treatment, $\mathrm{N}(\%)$ & $14(16.7)$ & $8(10.3)$ & 1.416 & 0.234 \\
\hline At least one SSRI, N (\%) & $58(69.0)$ & $60(76.9)$ & 1.268 & 0.260 \\
\hline Fluoxetine, N (\%) & $14(16.7)$ & $16(20.5)$ & 0.397 & 0.529 \\
\hline Mean FLX dose, mean \pm SD & $47.14 \pm 9.14$ & $47.50 \pm 8.56$ & -0.110 & 0.913 \\
\hline Fluvoxamine, N (\%) & $20(23.8)$ & $24(30.8)$ & 0.990 & 0.320 \\
\hline Mean FLUV dose, mean \pm SD & $255.00 \pm 48.40$ & $237.50 \pm 47.20$ & 1.211 & 0.233 \\
\hline Paroxetine, N (\%) & $12(14.3)$ & $10(12.8)$ & 0.074 & 0.786 \\
\hline Mean PAR dose, mean \pm SD & $46.00 \pm 5.16$ & $48.00 \pm 7.89$ & -0.671 & 0.511 \\
\hline Sertraline, N (\%) & $12(14.3)$ & $10(12.8)$ & 0.074 & 0.786 \\
\hline Mean SERT dose, mean \pm SD & $179.17 \pm 23.44$ & $180.00 \pm 25.82$ & -0.079 & 0.215 \\
\hline Clomipramine, N (\%) & $12(14.3)$ & $10(12.8)$ & 0.074 & 0.786 \\
\hline Mean CMI dose, mean \pm SD & $183.33 \pm 35.89$ & $190.00 \pm 26.87$ & -0.484 & 0.633 \\
\hline At least one AP, N (\%) & $20(23.8)$ & $24(30.8)$ & 0.990 & 0.320 \\
\hline Aripiprazole, N (\%) & $6(7.1)$ & $8(10.3)$ & 0.497 & 0.481 \\
\hline Mean ARI dose, mean \pm SD & $10.00 \pm 0.00$ & $11.25 \pm 2.32$ & -1.309 & 0.215 \\
\hline Risperidone, N (\%) & $8(9.5)$ & $8(10.3)$ & 0.024 & 0.876 \\
\hline Mean RISP dose, mean \pm SD & $1.50 \pm 0.54$ & $2.00 \pm 0.76$ & -1.528 & 0.149 \\
\hline Olanzapine, N (\%) & $6(7.1)$ & $8(10.3)$ & 0.497 & 0.481 \\
\hline Mean OLA dose, mean \pm SD & $5.83 \pm 1.29$ & $5.63 \pm 2.91$ & 0.162 & 0.874 \\
\hline
\end{tabular}

OCD: Obsessive-Compulsive Disorder, GMC: General Medical Condition, N: number, SD: standard deviation, SSRI: Selective Serotonin Reuptake Inhibitor, FLX: fluoxetine, FLUV: fluvoxamine, PAR: paroxetine, SERT: sertraline, CMI: clomipramine, AP: antipsychotic, ARI: aripiprazole, RISP: risperidone, OLA: olanzapine

rect comparison, this prevalence is similar to that observed in the Italian general population (16-17.8\%). However, the mean age of our sample was 35.6 years, and the result of a prevalence rate of nearly $20 \%$ of MetS in this group is of clinical relevance. The age-adjusted prevalence of MetS in the US general population is $27.0 \%,{ }^{28}$ while European studies have found lower rates, between $8 \%$ and $17.8 \%{ }^{29-32} \mathrm{~A}$ recent study, conducted on 97 patients with severe OCD, showed a similar prevalence of endocrine/metabolic diseases (23.7\%). ${ }^{33}$

There is a strong association between weight gain, obesity or metabolic abnormalities and psychopharmacological treatments, particularly second-generation antipsychotics (i.e. olanzapine or asenapine or quetiapine) and antidepressants with high H1-histamine receptor affinity (i.e. tricyclics and mirtazapine) due to counteracting the central anorexigenic effects of histamine or increasing adipose tissue deposition. ${ }^{34} \mathrm{~A}$ metaanalysis based on 116 studies employing most marketed antidepressants highlighted that different antidepressant medications greatly differ in affecting body weight. The authors found that tricyclics and mirtazapine were associated with the maximum weight gain, where most SSRIs, SNRIs and bupropion induced very little, if anything, weight gain. ${ }^{35}$ On the other hand, a systematic review recently highlighted the association between use of antidepressants and new onset type
2 diabetes. ${ }^{36}$ Together with illness-related factors such as the adoption of unhealthy lifestyles and probably inherited biological factors, specific pharmacological treatments could play a significant role in leading to the MetS..$^{34,37-39}$

Our prevalence rates of cardio-vascular and neurological diseases are comparable of those found in subjects with mental disorders by a population study conducted in Singapore. ${ }^{2}$ Despite these similarities, we found lower prevalence rates of cardio-vascular, musculoskeletal, respiratory, genitourinary and neurological disorders compared to other studies and higher prevalence rate on gastrointestinal diseases. ${ }^{33,40}$ This result could be explained by different methodology used and sample recruitment: for example, Drummond and coworkers considered only patients with severe OCD (subjects with severe OCD could have more physical burden).

The prevalence of any GMCs or a specific class of GMCs in a sample of subjects with a given psychiatric disorder has to be interpreted also comparing these rates with those in other psychiatric disorders.

The relationship between GMCs and major depression disorder was investigated in the Sequenced Treatment Alternatives to Relieve Depression (STAR*D) study. The prevalence of significant medical comorbidity in this population was $52.8 \%$, similar to that found in our OCD population; concurrent GMCs 
appeared to influence the severity and symptom patterns in MDD. $^{41}$

Compared to depression, the link between anxiety disorders and physical health is relatively understudied. Individuals with elevated anxiety are more likely than those without anxiety to have a wide array of medical conditions, including cardiovascular, autoimmune, and neurodegenerative diseases, and are at greater risk for early mortality. ${ }^{42}$ In a large community sample $(n=42,249)$, people diagnosed with anxiety disorders were more likely to have a variety of medical conditions in- cluding obesity (OR 1.2), diabetes (OR 1.3), asthma (OR 1.6), hypertension (OR 1.7), arthritis (OR 1.7), ulcer (OR 1.9), back/ neck problems (OR 2.0), heart disease (OR 2.0), headache (OR 2.3), and multiple pains (OR 2.3). ${ }^{43}$

When examining socio-demographic and clinical characteristics potentially associated with GMCs in patients with OCD, firstly we found a significant association with female gender and older age. This result was quite expected: as a matter of fact, it is obvious that older age implies higher probability of experiencing GMCs. Moreover, females patients in our sample

Table 3. Socio-demographic and clinical differences between OCD with/without GMCs

\begin{tabular}{|c|c|c|c|c|}
\hline & No GMCs $(\mathrm{N}=84)$ & GMCs $(\mathrm{N}=78)$ & $t / \chi^{2}$ & $\mathrm{p}$ \\
\hline Male gender, N (\%) & $62(73.8)$ & $34(43.6)$ & 7.649 & 0.006 \\
\hline Age (years), mean $\pm S D$ & $29.7 \pm 10.6$ & $42.0 \pm 15.4$ & -4.211 & $<0.001$ \\
\hline Education (years), mean $\pm S D$ & $12.9 \pm 3.3$ & $12.4 \pm 4.1$ & 0.609 & 0.156 \\
\hline Marital status, N (\%) & & & 4.140 & 0.247 \\
\hline Single & $62(73.8)$ & $46(59.0)$ & & \\
\hline Married & $18(21.4)$ & $26(33.3)$ & & \\
\hline Separated & $4(4.8)$ & $2(2.6)$ & & \\
\hline Widoved & $0(0.0)$ & $4(5.1)$ & & \\
\hline Occupational status, N (\%) & $58(69.0)$ & $40(51.3)$ & 2.671 & 0.102 \\
\hline Age at onset (years), mean $\pm S D$ & $18.2 \pm 7.7$ & $20.5 \pm 6.8$ & -1.432 & 0.156 \\
\hline Duration of untreated illness (years), mean \pm SD & $77.0 \pm 80.7$ & $153.0 \pm 134.9$ & -3.101 & 0.003 \\
\hline Cigarette smoking, N (\%) & $22(26.2)$ & $18(23.1)$ & 0.105 & 0.745 \\
\hline Physical activity, N (\%) & $64(76.2)$ & $40(51.3)$ & 5.459 & 0.019 \\
\hline Absent & $20(23.8)$ & $38(48.7)$ & & \\
\hline Mild & $40(47.6)$ & $26(33.3)$ & & \\
\hline Moderate & $16(19.0)$ & $14(17.9)$ & & \\
\hline Severe & $8(9.5)$ & $0(0.0)$ & 8.245 & 0.041 \\
\hline Y-BOCS, mean \pm SD & $26.3 \pm 6.2$ & $24.9 \pm 6.0$ & 1.044 & 0.299 \\
\hline Obsession score & $13.2 \pm 3.2$ & $12.7 \pm 2.9$ & 0.733 & 0.465 \\
\hline Compulsion score & $13.1 \pm 3.5$ & $12.2 \pm 3.6$ & 1.166 & 0.247 \\
\hline Hamilton Depression Rating Scale, mean \pm SD & $11.7 \pm 5.9$ & $11.8 \pm 6.8$ & -0.073 & 0.942 \\
\hline Hamilton Anxiety Rating Scale, mean \pm SD & $11.2 \pm 5.5$ & $11.5 \pm 5.6$ & -0.281 & 0.780 \\
\hline Clinical Global Illness-Severity, mean \pm SD & $3.8 \pm 0.9$ & $3.8 \pm 0.9$ & -0.036 & 0.971 \\
\hline Body Mass Index, mean \pm SD & $25.4 \pm 4.9$ & $26.0 \pm 6.1$ & -0.532 & 0.596 \\
\hline
\end{tabular}

OCD: Obsessive-Compulsive Disorder, GMC: General Medical Condition, N: number, SD: standard deviation, Y-BOCS: Yale-Brown Obsessive Compulsive Scale

Table 4. Relationship between potential explanatory variables and presence of GMCs in patients with OCD: results from the stepwise logistic regression analysis

\begin{tabular}{clrrrrrrc}
\hline Step & \multicolumn{1}{c}{ Variables } & \multicolumn{1}{c}{ T } & E.S. & Wald & df & p & Exp (B) & 95\% CI for EXP \\
\hline Step 1 & Gender & -0.842 & 0.391 & 4.627 & 1 & 0.031 & 0.431 & $0.200-0.928$ \\
Step 2 & Age & 0.058 & 0.017 & 11.780 & 1 & 0.001 & 1.059 & $1.025-1.095$ \\
Step 3 & Duration of untreated illness & 0.002 & 0.002 & 0.693 & 1 & 0.405 & 1.002 & $0.998-1.006$ \\
Step 4 & Physical activity & 1.306 & 0.395 & 10.952 & 1 & 0.001 & 3.693 & $1.704-8.007$ \\
& Constant & -2.290 & 0.678 & 11.404 & 1 & 0.001 & 0.101 & \\
\hline
\end{tabular}

OCD: Obsessive-Compulsive Disorder, GMC: General Medical Condition 
were older than males, although this difference was not statistically significant (data not shown), and this might in part explain the association between female gender and higher rate of GMCs. As we did not include a comparison group without OCD (e.g., from the general population), we cannot conclude that OCD is per se at higher risk of having a GMC beyond the effect of age. However, we do think that clinicians should be aware that approximately half of OCD patients do display a comorbid GMC that needs careful examination and treatment.

Secondly, patients with OCD and comorbid GMCs showed a higher DUI. To the best our knowledge, this is the first study to find an association between a longer DUI and the presence of GMCs in patients with OCD. Although this issue has been adequately studied in patients with schizophrenia and bipolar disorder, to date, only few studies showed the negative impact of a longer DUI in OCD. In previous studies, a longer DUI was significantly associated with poor treatment response (DUI $>24$ months), ${ }^{44}$ specific obsessive-compulsive dimensions (aggressive/checking dimension), ${ }^{45}$ older age, early age at onset, and older age of first pharmacological treatment (DUI $>4$ years). A shorter DUI ( $<4$ years) was associated with abrupt onset of OCD, precipitated by life events. ${ }^{46}$ Although the longer DUI no longer predicted the presence of a GMC in the logistic regression analysis, we consider our results worth to be discussed; it is possible that subjects not appropriately treated for years (longer DUI) display unhealthy lifestyles, or have poor access to the healthcare system even for general medical conditions or medical complications of severe OC symptoms (e.g., excessive hand or body washing leading to dermatological problems, avoidance of medical consultations for fear of contamination leading to failure to get appropriate diagnosis and treatment of an independent medical problem). Another explanation is based on alteration of hormonal system due to higher levels of stress that lead to an increase in cortisol levels and consequently poor glucose tolerance and obesity, diabetes, and hypertension. This in turn might lead to an increased risk to develop some GMCs, especially endocrine and cardiovascular diseases.

Lastly, GMCs in patients with OCD were significantly associated with the absence of physical activity. In our sample, fifty-eight patients (35.8\%) did not engage in any physical activity. It is known that a lack of physical activity is associated with anxiety disorders while physical inactivity is associated with many chronic physical diseases, ${ }^{47-49}$ It could be suggested that subjects with OCD are at increased risk to develop GMCs at least in part through physical inactivity.

The benefits of physical activity are well known and are summarized as follows: it promotes fat oxidation reducing the risk of obesity (important cardio-vascular risk factor and core component of MetS), improves insulin sensitivity thus reducing the risk of type 2 diabetes, prevents hypercholesterolemia and/or hypertension reducing the risk of heart disease or several cancers or premature death caused by heart attacks, decreases, in particular among children and young people, risky behaviors such as use of tobacco or alcohol, unhealthy diets, eases anxiety management and stressful situations, reduces the risk of osteoporosis and fractures but also musculoskeletal disorders (e.g., back pain). In the general population, physical activity has been shown to be the optimal strategy to improve both cardio-metabolic parameters and cardiorespiratory fitness levels. Psychoeducational programs are well structured in patients with bipolar disorder and schizophrenia. ${ }^{50-53}$ The improvement of anxiety symptoms due to physical activity has been studied in patients with anxiety disorders ${ }^{54}$ : in our opinion, these programs should be tested also in patients with OCD to see whether MetS could be prevented.

Obviously, the impact of GMCs associated with OCD is intuitively relevant for several reasons such as a worsened quality of life and functioning, an higher utilization of healthcare resources, and an increased risk of hospitalization and mortality: this supports the need for a proper functioning of healthcare integrated system. A recent population study conducted by Witthauer and coworkers on 4,181 subjects (aged 18-65), evaluated the association between GMCs and subjects with clinical and subthreshold OCD. The authors reported that subjects with both OC symptoms and GMCs reported the highest number of days of disability due to physical or psychological problems during the past 30 days compared to subjects with only OC symptoms, only GMC or neither of them. ${ }^{40}$ Less access to care, a no integrated health care system, patient difficulties to clearly describe medical symptoms, and patient shame feelings to discuss some clinical features lead to less attention in the fully evaluation and management of GMC in patients with major psychiatric disorders such as bipolar disorder and schizophrenia. ${ }^{55-57}$

The reader should be mindful of a number of limitations in the current study when interpreting our findings. The first one is the cross-sectional design that does not allow inferences on the temporal relationship between the variables and only shows measures of association. Secondly, the lack of a control group from another psychiatric population or the general Italian population. Another limitation is the small sample size recruited for the present study. However, our aim was to look for significant correlations between the presence of GMCs and clinical variables in patients with OCD, and therefore, an healthy group was not needed.

In conclusion, this study emphasizes the need to ensure that GMCs are not overlooked in psychiatric patients in gen- 
eral and in subjects with OCD in particular. We cannot conclude that the prevalence of GMCs is higher in OCD patients as compared to the Italian general population, but the rate of $48.1 \%$ in a sample with a mean age of 35.6 years is, to our opinion, clinically relevant. Assessment plus management of GMCs in patients with OCD are basic clinical factors in achieving satisfactory medical and psychiatric outcomes, in terms of stability, treatment adherence, life expectancy as well as quality of life, of these generally disadvantaged populations worldwide. Therefore, all patients should receive adequate evaluation and surveillance of GMCs and this process should be particularly made when patients with OCD are treated with second-generation antipsychotics as augmentation to antiobsessive medications. It might help clinicians and general practitioners to be sensitized for a better dissemination of integrated care system in order to recognize and to accomplish secondary prevention of potentially severe medical complications.

\section{REFERENCES}

1. Kessler RC, Berglund P, Chiu WT, Demler O, Heeringa S, Hiripi E, et al. The US National Comorbidity Survey Replication (NCS-R): design and field procedures. Int J Methods Psych Res 2004;13:69-92.

2. Chong SA, Abdin E, Nan L, Vaingankar JA, Subramaniam M. Prevalence and impact of mental and physical comorbidity in the adult Singapore population. Ann Acad Med Singapore 2012;41:105-114.

3. Scott K, Bruffaerts R, Tsang A, Ormel J, Alonso J, Angermeyer MC, et al. Depression-anxiety relationships with chronic physical conditions: results from the World Mental Health Surveys. J Affect Disord 2007; 103:113-120.

4. De Hert M, Dekker JM, Wood D, Kahl KG, Holt RI, Moller HJ. Cardiovascular disease and diabetes in people with severe mental illness position statement from the European Psychiatric Association (EPA), supported by the European Association for the Study of Diabetes (EASD) and the European Society of Cardiology (ESC). Eur Psychiatry 2009;24:412-424.

5. De Hert M, Correll CU, Bobes J, Cetkovich-Bakmas M, Cohen D, Asai I, et al. Physical illness in patients with severe mental disorders. I. Prevalence, impact of medications and disparities in health care. World Psychiatry 2011;10:52-77.

6. Aguglia A, Salvi V, Maina G, Rossetto I, Aguglia E. Fibromyalgia syndrome and depressive symptoms: comorbidity and clinical correlates. J Affect Disord 2011;128:262-266.

7. Weber NS, Fisher JA, Cowan DN, Niebuhr DW. Psychiatric and general medical conditions comorbid with bipolar disorder in the national hospital Discharge Survey. Psychiatry Serv 2011;62:1152-1158.

8. Maina G, Bechon E, Rigardetto S, Salvi V. General medical conditions are associated with delay to treatment in patients with bipolar disorder. Psychosomatics 2013;54:437-442.

9. Mansur RB, Brietzke E, McIntyre RS. Is there a "metabolic-mood syndrome"? A review of the relationship between obesity and mood disorders. Neurosci Bio Behav Rev 2015;52:89-104.

10. Magalhaes PV, Kapczinski F, Nierenber AA, Deckersbach T, Weisinger D, Dodd S, et al. Illness burden and medical comorbidity in the Systematic Treatment Enhancement Program for Bipolar Disorder. Acta Psychiatr Scand 2012;125:303-308.

11. Crump C, Sundquist K, Winkleby MA, Sundquist J. Comorbidities and mortality in bipolar disorder: a Swedish national cohort study.
JAMA Psychiatry 2013;70:931-939.

12. Cosci F, Fava GA, Sonino N. Mood and anxiety disorders as early manifestations of medical illness: a systematic review. Psychother Psychosom 2015;84:22-29.

13. Katon W, Lin EH, Kroenke K. The association of depression and anxiety with medical symptom burden in patients with chronic medical illness. Gen Hosp Psychiatry 2007;29:147-155.

14. Roy-Byrne PP, Davidson KW, Kessler RC, Asmundson GJ, Goodwin $\mathrm{RD}$, Kubzansky L, et al. Anxiety disorders and comorbid medical illness. Gen Hosp Psychiatry 2008;30:208-225.

15. Culpepper L. Generalized anxiety disorder and medical illness. J Clin Psychiatry 2009;70(Suppl 2):20-24.

16. Mussell M, Kroenke K, Spitzer RL, Williams JB, Herzog W, Löwe B. Gastrointestinal symptoms in primary care: prevalence and association with depression and anxiety. J Psychosomatic Res 2008;64:605-612.

17. Goulart AC, Santos IS, Brunoni AR, Nunes MA, Passos VM, Griep $\mathrm{RH}$, et al. Migraine headaches and mood/anxiety disorders in the ELSA Brazil. Headache 2014;54:1310-1319.

18. Kinley DJ, Lowry H, Katz C, Jacobi F, Jassal DS, Sareen J. Depression and anxiety disorders and the link to physician diagnosed cardiac disease and metabolic risk factors. Gen Hosp Psychiatry 2015;37:288-293.

19. Jakovljević M, Babić D, Crncević Z, Martinac M, Maslov B, Topić R. Metabolic syndrome and depression in war veterans with post-traumatic stress disorder. Psychiatr Danub 2008;20:406-410.

20. Carroll D, Phillips AC, Thomas GN, Gale CR, Deary I, Batty GD. Generalized anxiety disorder is associated with metabolic syndrome in the Vietnam experience study. Biol Psychiatry 2009;66:91-93.

21. Heppner PS, Crawford EF, Haji UA, Afari N, Hauger RL, Dashevsky BA, et al. The association of posttraumatic stress disorder and metabolic syndrome: a study of increased health risk in veterans. BMC Med 2009; $7: 1$.

22. Weiss T, Skelton K, Phifer J, Jovanovic T, Gillespie CF, Smith A, et al. Post-traumatic stress disorder is a risk factor for metabolic syndrome in an impoverished urban population. Gen Hosp Psychiatry 2011;33: 135-142.

23. Albert U, Aguglia A, Chiarle A, Bogetto F, Maina G. Metabolic syndrome and obsessive-compulsive disorder: a naturalistic Italian study. Gen Hosp Psychiatry 2013;35:154-159.

24. Matsunaga H, Nagata T, Hayashida K, Ohya K, Kiriike N, Stein DJ. A long-term trial of the effectiveness and safety of atypical antipsychotic agents in augmenting SSRI-refractory obsessive-compulsive disorder. J Clin Psychiatry 2009;70:863-868.

25. Maina G, Albert U, Salvi V, Bogetto F. Weight gain during long-term treatment of obsessive-compulsive disorder: a prospective comparison between serotonin reuptake inhibitors. J Clin Psychiatry 2004;65:13651371.

26. Linn BS, Linn MW, Gurel L. Cumulative illness rating scale. J Am Geriatr Soc 1968;16:622-626.

27. Sareen J, Jacobi F, Cox BJ, Belik SL, Clara I, Stein MB. Disability and poor quality of life associated with comorbid anxiety disorders and physical conditions. Arch Int Med 2006;166:2109-2116.

28. Ford ES, Giles WH, Mokdad AH. Increasing prevalence of the metabolic syndrome among U.S. adults. Diabetes Care 2004;27:2444-2449.

29. Balkau B, Vernay M, Mhamdi L, Novak M, Arondel D, Vol S, et al. The incidence and persistence of the NCEP (National Cholesterol Education Program) metabolic syndrome. The French D.E.S.I.R. study. Diabetes Metab 2003;29:526-532.

30. Hu G, Qiao Q, Tuomilehto J, Balkau B, Borch-Johnsen K, Pyorala K, et al. Prevalence of the metabolic syndrome and its relation to all-cause and cardiovascular mortality in non-diabetic European men and women. Arch Intern Med 2004; 64:1066-1076.

31. Miccoli R, Bianchi C, Odoguardi L, Penno G, Caricato F, Giovannitti MG, et al. Prevalence of the metabolic syndrome among Italian adults according to ATP III definition. Nutr Metab Cardiovasc Dis 2005;15: 250-254. 
32. Pérez Jiménez F, Mora Navarro G, Díez Espino J. Epidemiología. Impacto del síndrome metabólico en la salud pública en España. Med Clin Monogr (Barc) 2006;7:8-12.

33. Drummond LM, Boschen MJ, Cullimore J, Khan-Hameed A, White S, Ion R. Physical complications of severe, chronic obsessive-compulsive disorder: a comparison with general psychiatric inpatients. Gen Hosp Psychiatry 2012;34:618-625.

34. Salvi V, Barone-Adesi F, D’Ambrosio V, Albert U, Maina G. High H1-affinity antidepressants and risk of metabolic syndrome in bipolar disorder. Psychopharmacology 2016;233:49-56.

35. Serretti A, Mandelli L. Antidepressants and body weight: a comprehensive review and meta-analysis. J Clin Psychiatry 2010;71:1259-1272.

36. Barnard K, Peveler RC, Holt RI. Antidepressant medication as a risk factor for type 2 diabetes and impaired glucose regulation: systematic review. Diabetes Care 2013;36:3337-3345.

37. Guan N, Liu H, Diao F, Zhang J, Zhang M, Wu T. Prevalence of metabolic syndrome in bipolar patients initiating acute-phase treatment: a 6-month follow up. Psychiatry Clin Neurosci 2010;64:625-633.

38. Salvi V, D’Ambrosio V, Bogetto F, Maina G. Metabolic syndrome in Italian patients with bipolar disorder: a 2-year follow-up study. J Affect Disord 2012;136:599-603.

39. Salvi V, Mencacci C, Barone-Adesi F. H1-histamine receptor affinity predicts weight gain with antidepressants. Eur Neuropsychopharmacol 2016;26:1673-1677.

40. Witthauer C, Gloster A, Meyer AH, Lieb R. Physical diseases among persons with obsessive compulsive symptoms and disorder: a general population study. Soc Psychiatry Psychiatric Epidemiol 2014;49:20132022.

41. Yates WR, Mitchell J, Rush AJ, Trivedi MH, Wisniewski SR, Warden D, et al. Clinical features of depressed outpatients with and without cooccurring general medical conditions in STAR*D. Gen Hosp Psychiatry 2004;26:421-429.

42. Niles AN, Dour HJ, Stanton AL, Roy-Byrne PP, Stein MB, Sullivan G, et al. Anxiety and depressive symptoms and medical illness among adults with anxiety disorders. J Psychsom Res 2015;78:109-115.

43. Scott KM, Bruffaerts R, Tsang A, Ormel J, Alonso J, Angermeyer MC, et al. Depression-anxiety relationships with chronic physical conditions: results from the World Mental Health Surveys. J Affect Disord 2007;103:113-120.

44. Dell'Osso B, Buoli M, Hollander E, Altamura AC. Duration of untreated illness as a predictor of treatment response and remission in obsessive-compulsive disorder. World J Biol Psychiatry 2010;11:59-65.

45. Dell'Osso B, Benatti B, Oldani L, Spagnolin G, Altamura AC. Differ- ences in duration of untreated illness, duration, and severity of illness among clinical phenotypes of obsessive-compulsive disorder. CNS Spectrum 2015;20:474-478.

46. Poyraz CA, Turan Ş, Sağlam NG, Batun GÇ, Yassa A, Duran A. Factors associated with the duration of untreated illness among patients with obsessive-compulsive disorder. Compr Psychiatry 2015;58:88-93.

47. Panagiotakos DB, Pitsavos C, Lentzas Y, Skoumas Y, Papadimitriou L, Zeimbekis A, et al. Determinants of physical inactivity among men and women from Greece: a 5-year follow-up of the ATTICA study. Ann Epidemiol 2008;18:387-394.

48. Murray CJ, Atkinson C, Bhalla K, Birbeck G, Burstein R, Chou D, et al. The state of US health, 1990-2010: burden of diseases, injuries and risk factors. JAMA 2013;310:591-608.

49. Siddiqui F, Lindblad U, Bennet L. Physical inactivity is strongly associated with anxiety and depression in Iraqi immigrants to Sweden: a cross-sectional study. BMC Public Health 2014;14:502.

50. Sylvia LG, Nierenberg AA, Stange JP, Peckham AD, Deckersbach T. Development of an integrated psychosocial treatment to address the medical burden associated with bipolar disorder. J Psychiatr Pract 2011;17:224-232.

51. Sylvia LG, Salcedo S, Bernestein EE, Baek JH, Niereberg AA, Deckersbach T. Nutrition, Exercise, and Wellness Treatment in bipolar disorder: proof of concept for a consolidated intervention. Int J Bipolar Disord 2013;1:24.

52. Chalfoun C, Karelia AD, Stip E, Abdel-Baki A. Running for your life: A review of physical activity and cardiovascular disease risk reduction in individuals with schizophrenia. J Sports Sci 2016;34:1500-1515.

53. Salcedo S, Gold AK, Sheikh S, Marcus PH, Nierenberg AA, Deckersbach T, et al. Empirically supported psychosocial interventions for bipolar disorder: current state of the research. J Affect Disord 2016;201: 203-214.

54. Jayakody K, Gunadasa S, Hosker C. Exercise for anxiety disorders: systematic review. Br J Sports Med 2014;48:187-196.

55. Osborn DPJ, Levy G, Nazareth I, Petersen I, Islam A, King MB. Relative risk of cardiovascular and cancer mortality in people with severe mental illness from the United Kingdom's general practice research database. Arch Gen Psychiatry 2007;64:242-249.

56. Fagiolini A, Goracci A. The effects of undertreated chronic medical ilnesses in patients with severe mental disorders. J Clin Psychiatry 2009;70(Suppl 3):22-29.

57. Scott KM. Depression, anxiety and incident cardiometabolic diseases. Curr Opin Psychiatry 2014;27:289-293. 